\title{
Major Findings of the Angioplasty Procedure in Cohort of the Patients: A Epidemiological/Observational Study
}

Rodrigo Bottura Nuevo Viveiros de Araújo ${ }^{1}$, Wilson Pedro Guimarães Neto ${ }^{1}$, Júlio Cesar Queiroz de França ${ }^{1}$, Moacir Fernandes de Godoy ${ }^{2}$ Márcio Antônio dos Santos ${ }^{1}$, Flávio Corrêa Pivatelli ${ }^{1}$, Márcio Rogério de Souza Braite ${ }^{1}$, Ana Valéria Garcia Ramirez ${ }^{3,4}$, Jair Baron Junior ${ }^{1}$, Idiberto José Zotarelli Filho ${ }^{3,5,6^{*}}$, Marcella Castro Torres ${ }^{7}$

${ }^{1}$ Department of Hemodynamics and Interventional Cardiology, Base Hospital, Medicine School of São Jose do Rio Preto/SP - FAMERP, Brazil.

${ }^{2}$ Department of Cardiology and Cardiovascuslar Surgery, Medicine School of São Jose do Rio Preto/SP - FAMERP, Brazil.

${ }^{3}$ Associação Brasileira de Nutrologia (ABRAN)/Brazilian Association of Nutrology, Catanduva/SP, Rua Belo Horizonte, 909 - Centro, Catanduva SP Brazil 15801-150.

${ }^{4}$ Clinic Ana Valeria Ramirez (CAVR)-Clinical of Nutrition and Health Science, Street Antônio José Martins Filho, 300, 10 floor, room 103, São José do Rio Preto SP, 15092-230, Brazil.

${ }^{5}$ FACERES - Faculty of Medicine of Sao Jose do Rio Preto/SP, Brazil.

${ }^{6}$ Zotarelli-Filho Scientific Work, Sao Jose do Rio Preto/SP, Brazil.

${ }^{7}$ Ambulatório Médico de Especialidades (AME)/Outpatient Specialty Clinics, Jales and Santa Fé do Sul, São Paulo, Brazil.

*Corresponding author: Idiberto José Zotarelli Filho, MSc, Ph.D. FACERES Medical School and Zotarelli-Filho Scientific Works of Sao Jose do Rio Preto/SP, Brazil,

\section{Received date: September 24, 2020; Accepted date: October 05, 2020; Published date: October 12, 2020}

Citation: Rodrigo Bottura Nuevo Viveiros de Araújo, Guimarães Neto WP, Júlio Cesar Queiroz de França, Moacir Fernandes de Godoy, Márcio Antônio dos Santos, Idiberto José Zotarelli Filho, Marcella Castro Torres. (2020) Major Findings of the Angioplasty Procedure in Cohort of the Patients: A Epidemiological/Observational Study. J, Clinical Cardiology and Cardiovascular Interventions, 3(9); Doi:10.31579/2641-0419/087

Copyright: (C) 2020 Idiberto José Zotarelli Filho, This is an open access article distributed under the Creative Commons Attribution License, which permits unrestricted use, distribution, and reproduction in any medium, provided the original work is properly cited.

\section{Abstract}

Introduction: According to data from the World Health Organization of 2017, of the 21.7 million deaths from these diseases, more than ten million occur due to atherosclerotic coronary disease. Objective: Therefore, the present study aimed to analyze the main clinical data in terms of coronary angiography findings, as well as to know if the types of lesions found are related to acute myocardial infarction and whether gender and age predictors influence these events.

Methods: A total of 502 participants (Female: $n=174$; Male: $n=328$ ) were submitted to eligibility analysis, followed by the rules STROBE. The present study followed a retrospective longitudinal with epidemiological/observational profile study on the analysis of the profile of patients who underwent angioplasty at Brazil. As there were continuous and categorical predictors and the response predictors, linear regression and was applied. For all linear regression tests, alpha level lower than 0.05 was adopted as significant.

Results and Conclusion: According to the results in the evaluated cohort of the present study, it can be known that the presence of lesions above $50.0 \%$ in the LCT, P. Descendant, Circumflex, Right Coronary, Saphenous Bridge did not imply the occurrence of Stable, AMI - ST events. (NOT), AMI-ST and Complications, with a significant statistical difference, $\mathrm{p}<0.05$, not finding any relationship between them. Moreover, it was observed that the Gender and Age predictors statistically influenced the response of the P. Descendant, Circumflex, Right Coronary and Complications predictors, with $\mathrm{p}<0.05$.

Key Words: cardiovascular disease; atherosclerosis; angioplasty; acute myocardial infarction.

\section{Introduction}

According to data from the World Health Organization of 2017, of the 21.7 million deaths from these diseases, more than ten million occur due to atherosclerotic coronary disease (ACD) [1]. In Brazil, it is responsible for large numbers of deaths and health care expenditures [2].

Furthermore, the coronary diseases (CD) resulting from occlusion or narrowing of the coronary arteries due to the formation of atherosclerotic plaques [3]. The CDs, responsible for about 384 thousands deaths per year in Brazil, are associated with a set of risk factors, including advanced age, gender, smoking, obesity, hypertension, diabetes, genetic factors, hypercholesterolemia and sedentary lifestyle [4].

The pathophysiological manifestation of $\mathrm{CD}$ involves coronary insufficiency, characterized by the imbalance between supply and consumption of oxygen at the myocyte level $[5,6]$. Thus, the goal of treatment of stable angina depends on increased myocardial oxygen supply and reduced demand, which are closely related to contractility, left ventricular parietal stress, myocardial mass, and heart rate and post-load variations determined by blood pressure [6,7]. 
Within the therapeutic arsenal for the treatment of acute myocardial infarction with ST segment elevation to the electrocardiogram, primary percutaneous coronary intervention is the most important reperfusion strategy [6-8]. However, its accomplishment within the deadlines defined in the evidence of the studies is a great challenge [25]. The diagnosis of $\mathrm{CD}$ is based on the association of clinical history and complementary examinations, since the majority of patients with $\mathrm{CD}$ present normal physical examination. Thus, complete anamnesis and evaluation of personal and family history are fundamental [9].

The treatment of acute myocardial infarction with ST-segment elevation is consolidated in the trinomial thrombolysis chemistry-primary angioplasty-salvage angioplasty [10]. Depending on the place of care and local conduct, these strategies work and lead to huge reductions in deaths and myocardial damage $[9,10]$. It is essential that the health system is organized to establish the best local strategy to obtain this enormous benefit of opening the artery responsible for the occluded infarct in the shortest time. The most used procedure for the treatment of coronary lesions is the angioplasty with stent implantation [10].

Therefore, the present study aimed to analyze the main clinical data in terms of coronary angiography findings, as well as to know if the types of lesions found are related to acute myocardial infarction and whether gender and age predictors influence these events.

\section{Methods}

\section{Participants}

A total of 502 participants (Female: $n=174$; Male: $n=328$ ) were submitted to eligibility analysis, followed by the rules STROBE (Strengthening the Reporting of Observational studies in Epidemiology), https://www.strobe-statement.org/index.php?id=strobe-home.

\section{Settings}

The study took place in Department of Hemodynamics and Interventional Cardiology, Base Hospital, Medicine School of São Jose do Rio Preto/SP - FAMERP, Brazil. A single doctor analyzed and placed the findings of interest to each patient in the spreadsheet. All data were strictly kept confidential.

\begin{tabular}{|l|c|c|c|c|c|}
\hline & LCT & P. Descendant & Circumflex & Right Coronary & Saphenous Bridge \\
\hline N (lesion)/ \% & $15 / 2.9$ & $279 / 55.6$ & $185 / 36.6$ & $207 / 41.2$ & $7 / 1.4$ \\
\hline N (no lesion)/ \% & $487 / 97.1$ & $223 / 44.4$ & $317 / 63.4$ & $295 / 58.8$ & $495 / 98.6$ \\
\hline & Stable & AMI-ST (NOT) & AMI-ST & Complications & \\
\hline N (Yes) / \% & $383 / 76.3$ & $86 / 17.1$ & $33 / 6.6$ & $5 / 1.0$ & \\
\hline N (No) / \% & $119 / 23.7$ & $416 / 82.9$ & $469 / 93.4$ & $497 / 99.0$ & \\
\hline
\end{tabular}

Table 1: General clinical data.

Table 2 shows the results of the analytical regression analysis for the statistical influence of the Gender and Age predictors on the LCT, P. Descendant, Circumflex, Right Coronary, Saphenous Bridge, Stable, AMI - ST (NOT), AMI- ST and Complications. Thus, the results showed

\begin{tabular}{|l|c|c|c|c|c|}
\hline & LCT & P. Descendant & Circumflex & Right Coronary & Saphenous Bridge \\
\hline Gender(p value) & 0.856 & 0.000 & 0.000 & 0.005 & 0.209 \\
\hline Age (p-value) & 0.351 & 0.000 & 0.012 & 0.000 & 0.942 \\
\hline & Stable & AMI-ST (NOT) & AMI-ST & Complications & \\
\hline Gender (p-value) & 0.714 & 0.997 & 0.572 & 0.050 & \\
\hline Age (p-value) & 0.234 & 0.509 & 0.758 & 0.015 & \\
\hline
\end{tabular}

Table 2: Regression analysis results, with $\mathrm{p}<0,05$ as significant.

Figures 1 to 5 present the results of the variance equality test (ANOVA) in relation to the statistical difference between the standard deviations of
Ethics

The study was reviewed and approved by Clinical Institutional Review Board of all the Clinics included in the study. All procedures performed in the study were in accordance with the ethical standards of the institutional research committee and with the 1964 Helsinki declaration and its later amendments or comparable ethical standards.

\section{Study Design}

The present study followed a retrospective longitudinal with epidemiological/observational profile study on the analysis of the profile of patients who underwent angioplasty at Brazil. The predictors were: Cardiovascular disease. Atherosclerosis. Angioplasty. Acute myocardial infarction.

\section{Statistical analysis}

Statistical analysis of the data was performed and interpreted by the author of the present study. For data analysis a database was built in the Microsoft Excel spreadsheet which was exported to the Minitab 18 statistical program. A common descriptive statistical analysis and Anderson-Darling normality test were performed for all variables and controls, with reference p> 0.10 as "normal". As there were continuous and categorical predictors and the response predictors, linear regression and was applied. For all linear regression tests, alpha level lower than 0.05 was adopted as significant.

\section{Results}

Based on the general clinical data found in the present study with a total of 502 patients, with a mean age of 65.04 years, with 174 women and 328 men. Still, 394 patients did not use a stent, only 10 patients used conventional stent and 98 used other stent types. In terms of access, 466 patients underwent radial and 36 femoral angioplasty.

According to Table 1, the other clinical data of the patients involved in the present study were presented, showing the values in absolute numerical data and percentage in relation to the predictors LCT, P. Descendant, Circumflex, Right Coronary, Saphenous Bridge, Stable, AMI-ST (NOT), AMI-ST and Complications.

that Gender and Age statistically influenced the response of predictors P. Descendant, Circumflex, Right Coronary and Complications, with $\mathrm{p}$ $<0.05$.

each predictor, analyzing whether the presence of lesions above $50.0 \%$ in the TCL, P. Descendant, Circumflex., Right Coronary, Saphenous Bridge 
implied the events of Stable, AMI - ST (NOT), AMI-ST and Complications. According to these results, it was observed that in all comparisons there was a statistically significant difference, with $\mathrm{p}<0.05$, not finding any relationship between them.

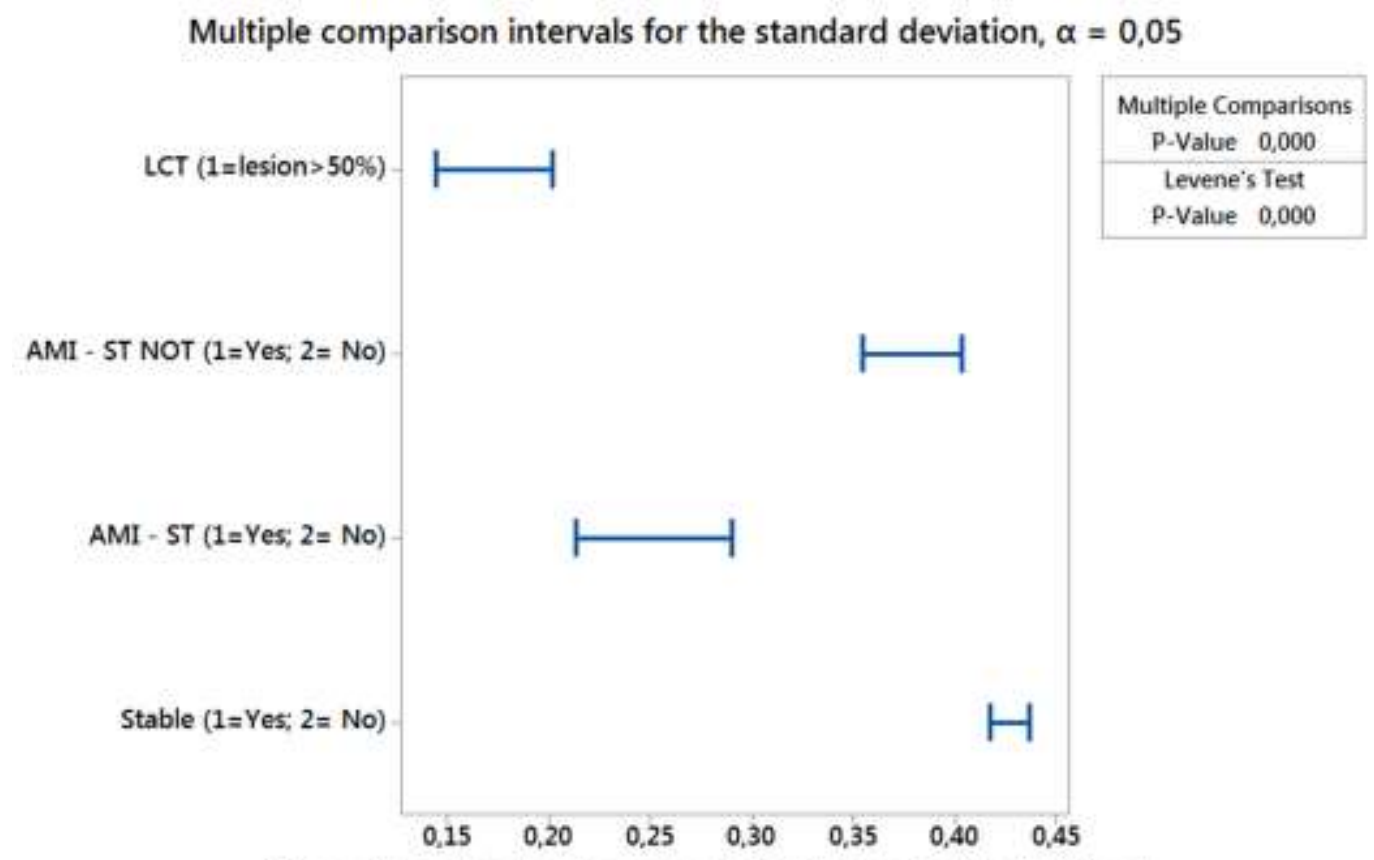

If intervals do not overlap, the corresponding stdevs are significantly different.

Figure 1: The test result of equality of variance test between LCT and Stable, AMI - ST (NOT), AMI-ST, with p <0.05 as statistically different.

Multiple comparison intervals for the standard deviation, $\alpha=0,05$

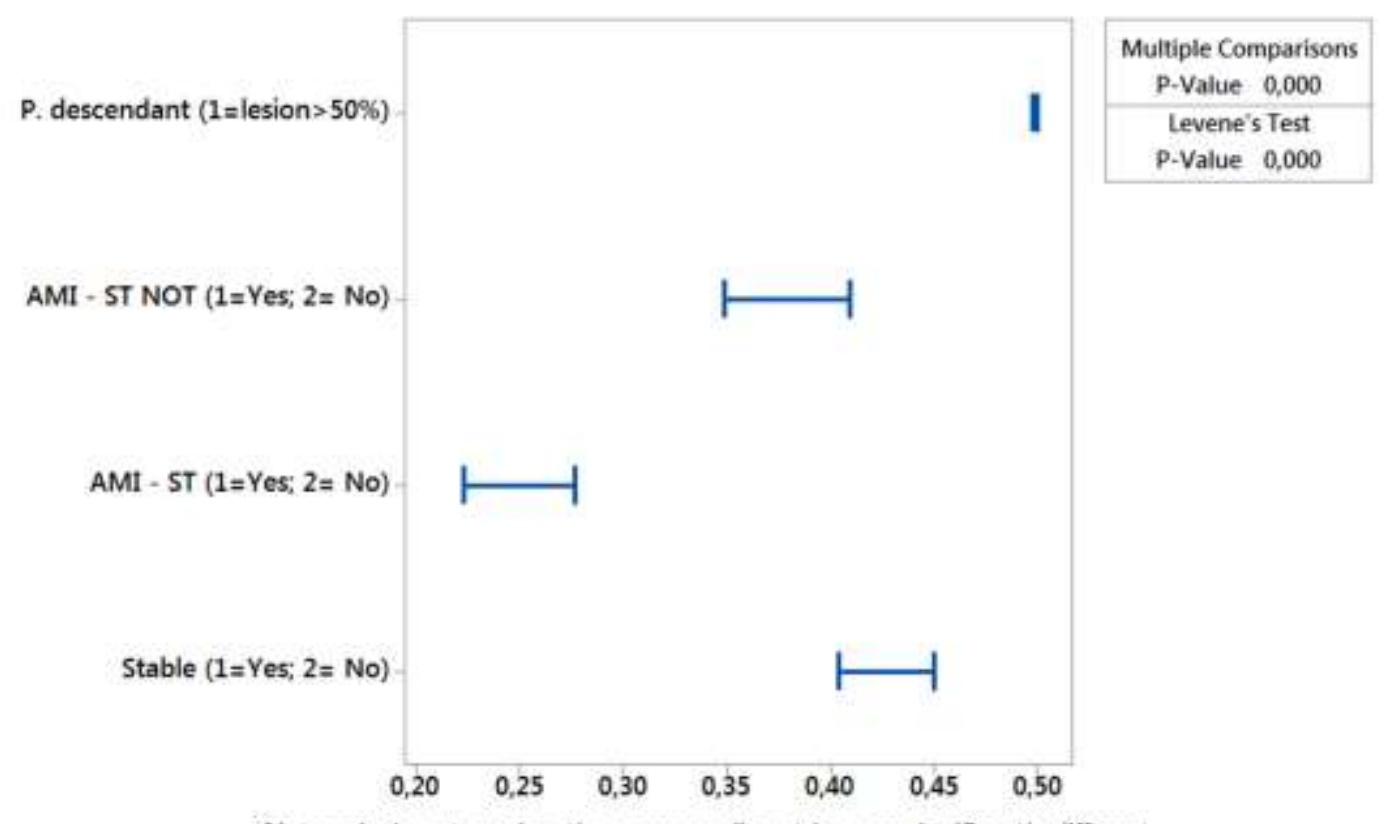

If intervals do not overlap, the corresponding stdevs are significantly different.

Figure 2: Result of the test of equality of variance between P. Descendant and Stable, AMI - ST (NOT), AMI-ST, with p <0.05 as statistically different. 


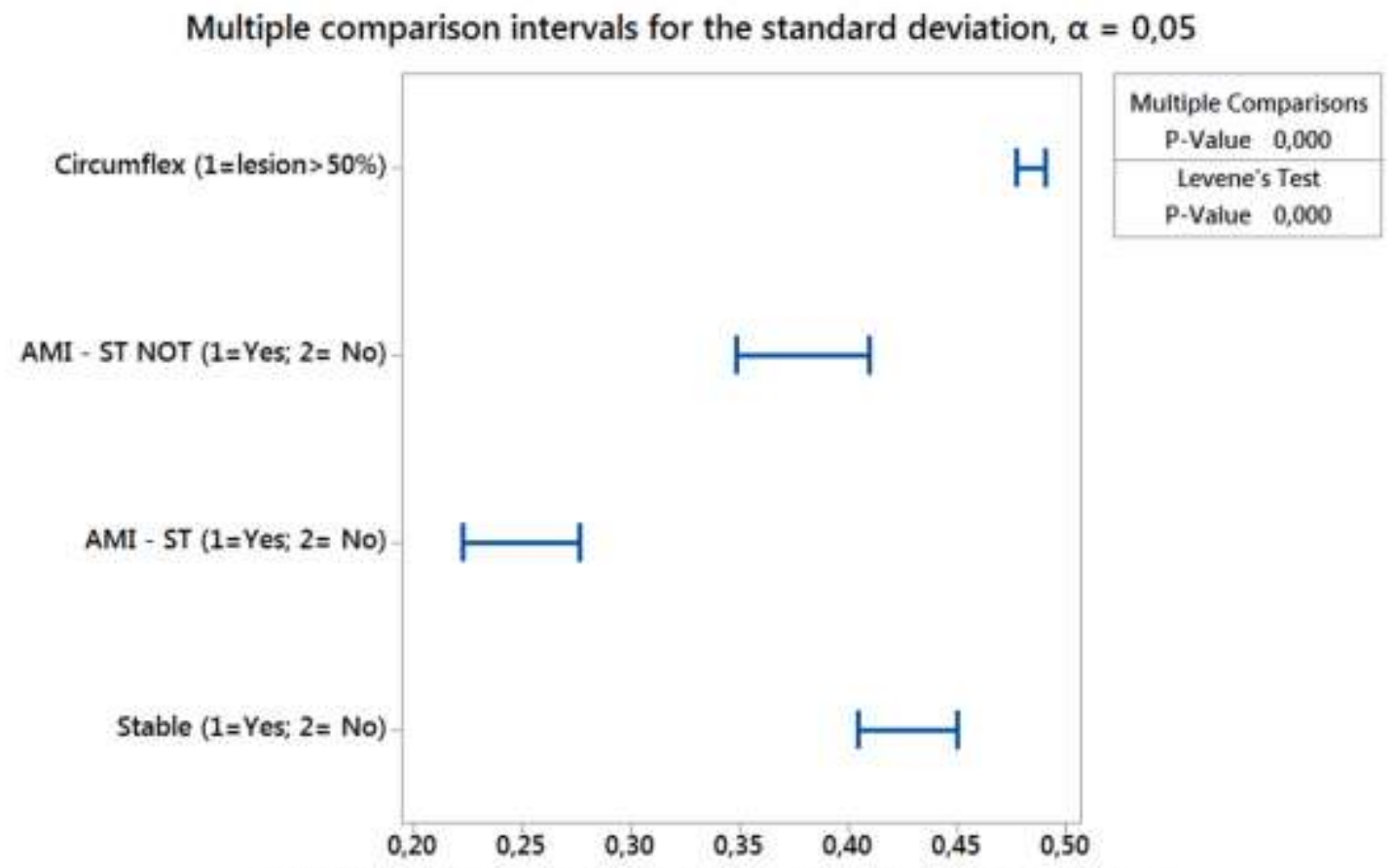

If intervals do not overlap, the corresponding stdevs are significantly different.

Figure 3: Result of the test of equality of variance between Circumflex and Stable, AMI - ST (NOT), AMI-ST, with p <0.05 as statistically different.

Multiple comparison intervals for the standard deviation, $\alpha=0,05$

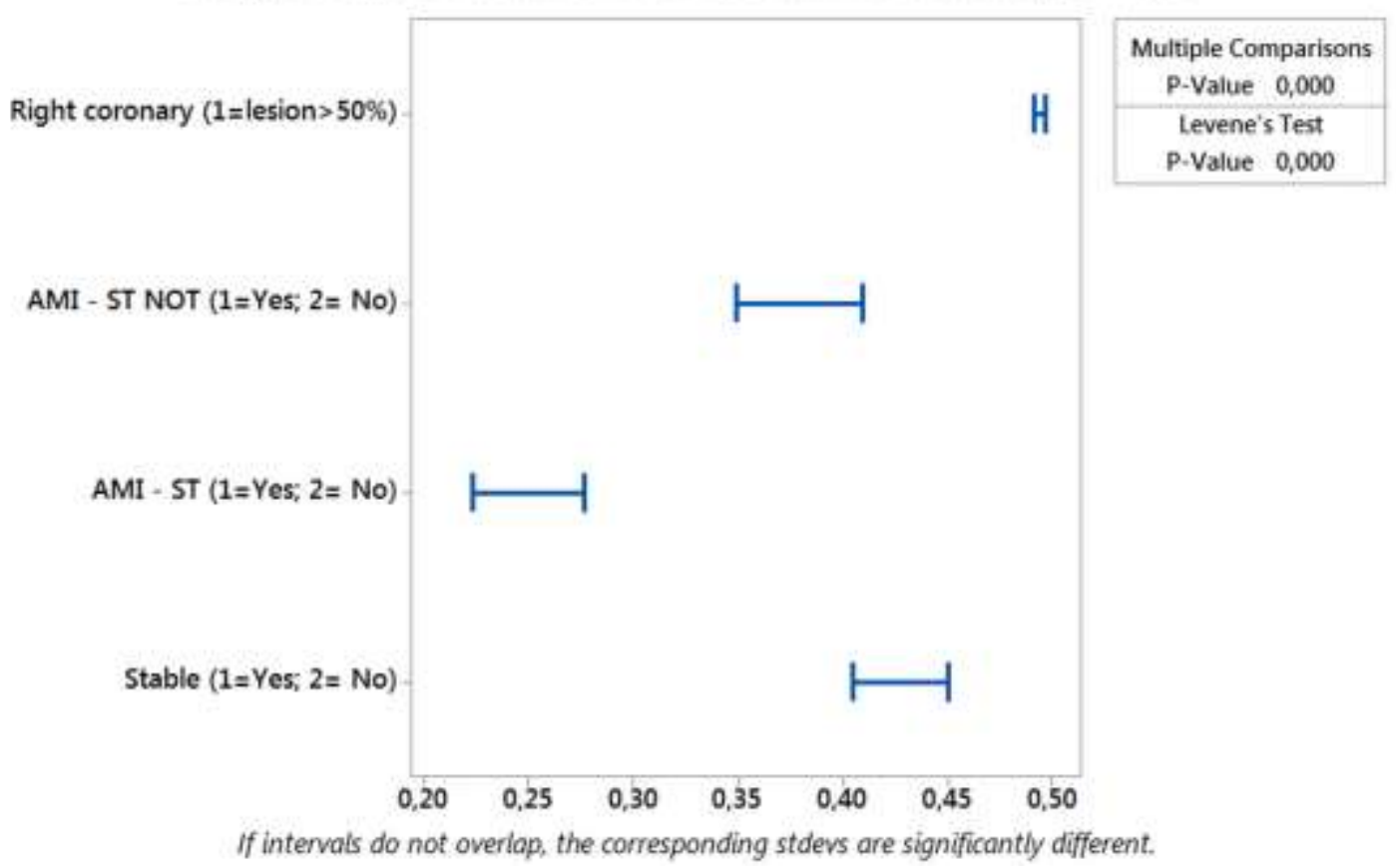

Figure 4. Result of the equality of variance test between Right coronary and Stable, AMI - ST (NOT), AMI-ST, with p <0.05 as statistically different. 


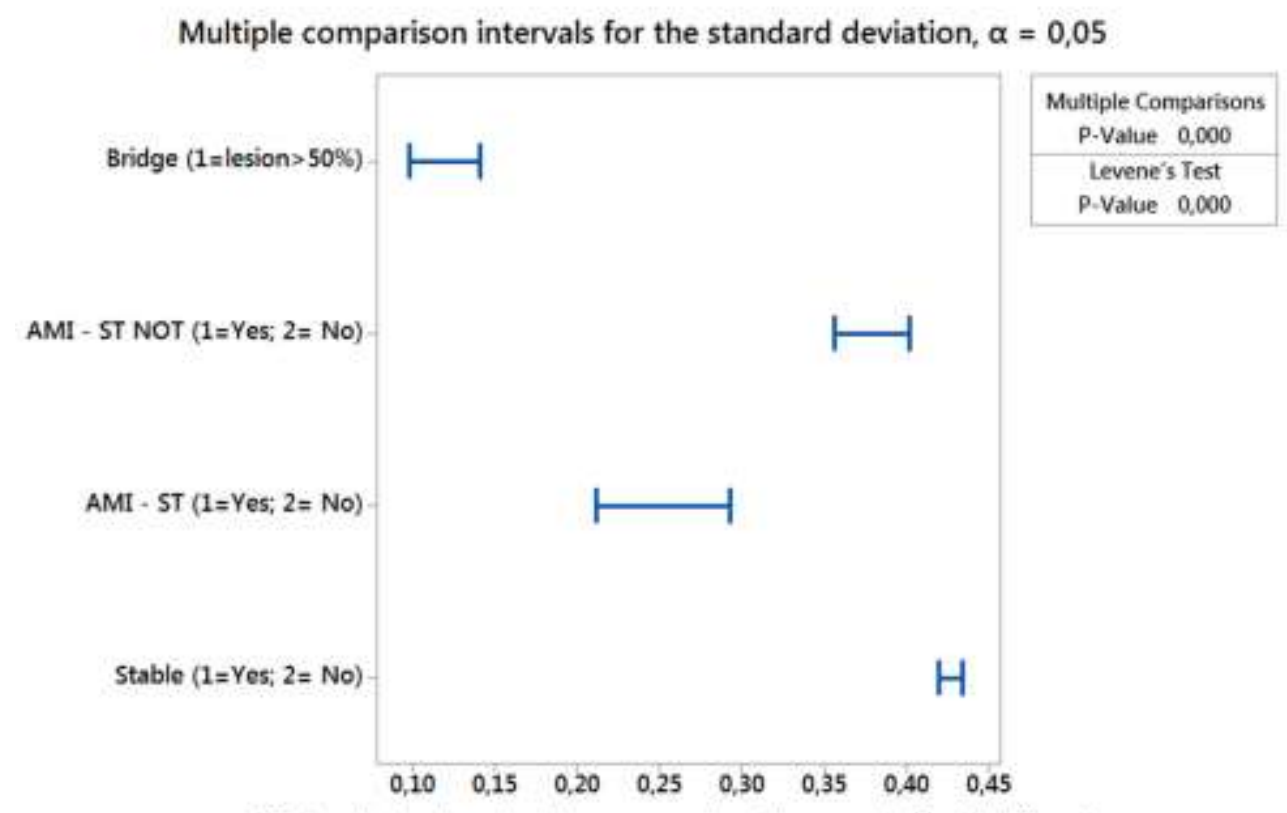

If intervals do not overlop, the corresponding stdevs are significantly different.

Figure 5: Result of the test of equality of variance between Saphenous Bridge and Stable, AMI - ST (NOT), AMI-ST, with p <0.05 as statistically different.

\section{Discussion}

According to the results in the evaluated cohort of the present study, it can be known that the presence of lesions above $50.0 \%$ in the LCT, P. Descendant, Circumflex, Right Coronary, Saphenous Bridge did not imply the occurrence of Stable, AMI - ST events. (NOT), AMI-ST and Complications, with a significant statistical difference, $\mathrm{p}<0.05$, not finding any relationship between them. Moreover, it was observed that the Gender and Age predictors statistically influenced the response of the P. Descendant, Circumflex, Right Coronary and Complications predictors, with $\mathrm{p}<0.05$.

In this scenario, coronary artery disease results in higher morbidity, mortality, and medical costs than any other illness in the developed world. The improvement of coronary artery disease non-invasive detection is still actual problem. According to Palmiero et al. (2019) [11], the primary prevention of cardiovascular events in the elderly is a relevant problem due to the lack of evidence for safe and effective therapy. Life expectancy has increased dramatically in the last two decades, the proportion of individuals 80 and older has grown rapidly in Europe and the United States. Therefore, it is important to implement the estimation of cardiovascular risk factors in the elderly for the patients' quality of life and to prolong their healthy life expectancy by choosing the best treatment for each patient, sharing the choice with himself whenever possible, always remembering elderly patients usually have multiple comorbidities that require a high number of medications, thus reducing the potential benefits of cardiovascular disease prevention [11].

It is not uncommon for patients who present with ACD without ST elevation to have no electrocardiographic or laboratory abnormalities. In view of this, adequate assessment of the probability of atherosclerotic disease is fundamental [3]. The presence of one or more risk factors for coronary atherosclerotic disease, considerably increases the possibility of being the patient with an acute myocardial ischemic disease. Older age, male gender, family history of coronary disease, diabetes, hyperlipidemia, hypertension, smoking, chronic renal failure, previous infarction or atherosclerotic or carotid disease are widely known risk factors [4].

The initial diagnosis of ACDs with supra ST is temporally confounded with its treatment. Due to the severity and drama of the disease, diagnosis and treatment go hand in hand, with no loss of time [5]. The central symptom of sudden cardiac arrest (SCA) with supra ST is chest pain that lasts for more than 20 minutes, which does not subside with rest, nor with the use of nitrates [6]. As in cases of ACDs without supra ST, the pain is usually in oppression, it can radiate to one or both arms, jaw or nape. Also in these cases there are those who present atypical symptoms, usually elderly, women or diabetics. For this reason, these patients, who may reach $30.0 \%$ of those who seek the emergency service, receive less frequently adequate therapy according to some analyzes [6,7].

The CT angiographic strategy reduced the time to diagnosis by $54.0 \%$ and the hospitalization costs by $38.0 \%$, without any difference in the rate of adverse events in relation to the scintigraphy strategy [4]. The purpose of the ACRIN-PA study was to evaluate the safety of CT angiography in the evaluation of patients with low and intermediate risk chest pain compared to the traditional approach. None of the patients with negative CT angiography had the primary endpoint analyzed, composed of cardiac death or infarction within the first 30 days after admission. In addition, patients in the angio-CT group had a higher rate of discharge from the emergency units (49.6\% vs. $22.7 \%$ ) and fewer days of hospitalization (18 hours vs. $24.8 \mathrm{~h}, \mathrm{p}<0.001$ ), without significant differences in the incidence of coronary angiography or revascularization in 30 days [4]. In addition, the term SCA is used in situations in which the patient presents clinical and/or laboratory evidence of acute myocardial ischemia, caused by an imbalance between supply and demand of oxygen to the 
myocardium, and the main cause is the instability of an atherosclerotic plaque. SCA presents in two clinical forms: ST-segment elevation (SCACSST), or acute myocardial infarction with ST-segment elevation (STEMI), and ST-segment elevation non-ST-segment elevation (SCASST) [7-9].

Patients with AMISST should be treated immediately with primary PCI (within 90 mins of admission). Patients with a formal contraindication to thrombolytic therapy should be transferred for primary PCI within $12 \mathrm{~h}$ of symptom onset. The best option for reperfusion therapy in AMISST is primary PCI. But the delay in achieving PCI reduces this advantage over thrombolytic therapy $[13,14]$. When this delay is greater than 60 minutes, the advantages equal. Thus, a strategy of prehospital chemical thrombolysis followed by planned PCI (for hemodynamically stable patients) or salvage PCI has shown results equivalent to or better than primary PCI for those patients presenting to the emergency department early [14].

Over the past two decades, several studies have compared invasive strategy to conservative (or selective invasive) strategy. In meta-analysis by Mehta et al [8] (7 studies, 9212 patients), the implementation of an invasive strategy resulted in an $18.0 \%$ reduction in the relative risk of non-fatal infarction and death $(14.4 \%$ vs $12.2 \%$, OR, 0.82 , 95\% CI 0.72 $0.93, \mathrm{p}=0.001)$. In a meta-analysis with 7 studies and 8375 patients, Bavry et al [28] revealed that the invasive strategy was associated with a $25.0 \%$ reduction in death $(4.9 \%$ vs $6.5 \%, \mathrm{RR}=0,95 \% \mathrm{CI} 0.63-0.90, \mathrm{p}=$ $0.001), 17.0 \%$ in non-fatal infarction rates $(7.6 \%$ vs $9.1 \%$, RR $0.83 \mathrm{CI}$ $95 \% 0.72-0,96)$ and $31 \%$ in rehospitalization due to unstable angina (RR $0.6995 \%$ CI $0.65-0.74)$.

In addition, a study reported techniques on single-stage angioplasty and left common carotid and left internal carotid artery ostium stent in an octogenarian man with the transient ischemic attack. Neurological examination showed transient left-sided visual obscurity or transient amaurosis and right hemiparesis. Duplex imaging of the carotid artery revealed $80 \%$ left internal carotid artery stenosis (LICA) and $95 \%$ left common carotid artery ostium (left CCA). Immediate brain magnetic resonance was not possible. Angioplasty and stenting of both lesions (left CCA and LICA) were successfully performed without complications in one session. The stent of the ostial lesion of the common carotid artery and internal carotid artery in one session could be performed even in the acute neurological phase and also in very elderly patients [12].

In addition, drug-coated balloon angioplasty (AD) has emerged as an effective management strategy worldwide. In June 2016, AD became available for the treatment of minor coronary lesions again in Japan; however, to date, there has been no multicenter analysis in a post-approval real-world clinical setting. Thus, a multicenter study from June 2016 to July 2017, involved a total of 111 lesions (102 patients) treated with AD for minor de novo coronary lesions were enrolled in six Japanese institutions. The primary endpoint was the target lesion revascularization rate at 12 months. Angiographic follow-up parameters were binary restenosis and late lumen loss. Follow-up clinical data at 12 months were available for 106 lesions, excluding five lesions requiring salvage stenting. The target lesion revascularization rate was 5.7\% (6/106 lesions). No cardiac death or thrombosis of the target lesion was observed. The binary restenosis rate was $14.4 \%$ and the LLL was $0.0017 \pm 0.37 \mathrm{~mm}$. $\mathrm{AD}$ angioplasty for small coronary lesions again in the real-world environment in Japan is effective with acceptable 12-month results [15].
A retained or retained coronary angioplasty guidewire is a rare but serious complication of coronary interventions. The failed attempt for percutaneous transluminal coronary angioplasty in the left anterior descending artery in a 35 -year-old man was complicated by entrapment of the guidewire. Under cardiopulmonary bypass and cardioplegic arrest, the entire length of the trapped guidewire was successfully recovered from the left anterior descending artery and the aorta through an aortotomy following revascularization with the left internal mammary artery [16].

Other study aimed to conduct a retrospective longitudinal and observational study on the impact of angioplasty procedure in patients older than 80 years and with anemia. A total of 185 participants were submitted to eligibility analysis. This study followed a retrospective longitudinal and observational model on the analysis of the profile of patients who underwent angioplasty at Brazil. The predictors were anemia and older patients. The multivariate analysis showed that anemic patients older than 80 years who underwent angioplasty died, with a significance level of $33.97 \%$ in the female group and $34.40 \%$ in the male group, with a total of $68.40 \%$ of deaths in statistical terms. The Graph matrix-Plot model showing the results of the regression analysis between continuous predictors and response, with $\mathrm{p}<0.05$ as significant. All the results showed $\mathrm{p}<0.05$ because the presence of the predictor "anemia" negatively influenced the angioplasty procedure in the patients. Thus, was showed that patients with anemia showed a significant increase in life risk with death occurring after an angioplasty procedure [17].

Therefore, a study aimed to conduct a retrospective longitudinal and observational study on the metabolic, behavioral and clinical profile of patients who underwent angioplasty. A total of 1035 participants were submitted to eligibility analysis, This study followed a retrospective longitudinal and observational model on the analysis of the profile profile of patients who underwent angioplasty at Santa Casa de Misericórdia Hospital, São José do Rio Preto, Brazil. The predictors were: clinical, coronary segment affected, laboratory abnormality, types of procedures, previous AMI, previous ATC, previous ATC / Actual ATC. The result of the statistical correlation of regression between the continuous predictors and the response was demonstrated by means of the MatrixPlot model graph. All analyzes presented statistical difference with $p>0.05$, except between the predictors segment affected x DM, laboratory abnormality $\mathrm{x}$ gender, laboratory abnormality $\mathrm{x}$ sedentary lifestyle, previous AMI x gender and previous ATC $\mathrm{x}$ ender. All the latter presented statistical significance, with $\mathrm{p}<0.05$.

Was confirmed the literary findings in the questions that involve the direct correlation between the main cardiovascular risk factors such as Diabetes mellitus, sedentary lifestyle, age, SAH, Nsmoking and dyslipidemia in the increase of angioplasty procedures [18]. And, lastly, a study aimed to increase the quality of non-invasive diagnostics of coronary artery disease with statistical technology of electrocardiogram (ECG) signal processing for quantitative assessment the degree of myocardial ischemia and the coronary artery lesion [17]. The four minutes 12-channel electrocardiogram was used for the statistical technology of ECG signal processing to gain $200 \mathrm{PQRST}$ complexes. It allowed calculating L criterion from relation of standard deviation to average value of $200 \mathrm{~T}$ wave times and G-criterion the from relation of standard deviation to 
average value of $200 \mathrm{~T}$-wave amplitudes in all 12 channels. The $\mathrm{L}$ and $\mathrm{G}$ criteria were compared by relation the maximum value in one channel to minimum value in another channel to get the second order L and $G$ criteria. Thus, 139 patients with suspected coronary artery disease underwent elective coronary angiography and were examined by $\mathrm{G}$ and $\mathrm{L}$ criteria. Among patients with coronary angiography the values of second order L-criterion had a strong positive correlation with the value of coronary artery lesion (correlation factor $r=+0.894$ ). The values of Gcriterion quantitatively reflect the severity of clinical presentation and confirm the functional classes. The electrocardiographic curve parameters allows indirectly assessing the coronary blood flow and the degree of ischemic process regardless the presence of risk factors and clinical presentation. The localization of maximum ischemic process according the appropriate leads can help in selection of stent implantation priority [19].

\section{Conclusion}

The presence of lesions above $50.0 \%$ in the LCT, P. Descendant, Circumflex, Right Coronary, and Saphenous Bridge did not imply the occurrence of Stable, AMI - ST events. (NOT), AMI-ST and Complications. Moreover, it was observed that the Gender and Age predictors statistically influenced the response of the P. Descendant, Circumflex, Right Coronary and Complications predictors.

\section{Declaration of Potential Conflict of Interest}

The authors declare no conflict of interest.

\section{Funding}

Not applicable

\section{Data sharing statement}

No additional data are available

\section{References}

1. World Health Organization (WHO). The top 10 causes of death. http://www. who.int/mediacentre/factsheets/fs310/en/accessed in 09/10/2019.

2. IBGE- Instituto Brasileiro de Geografia e Estatística. Disponível em: < http://www.ibge.gov.br>. Accessed in July of 2019.

3. Babunashvili AM, Dundua DP, Kartashov DS, Bazarnova AA, Korenevich AY, Vetluzhskikh ME. Coronary Angioplasty and Stenting in Patients Older Than 80 Years: Immediate and Long-Term Results. Kardiologiia. 2016 Jul;56(7):54-62.

4. Pang J, David Marais A, Blom DJ, Brice BC, Silva PR, Jannes CE, Pereira AC, Hooper AJ, Ray KK, Santos RD, Watts GF. Heterozygous familial hypercholesterolaemia in specialist centres in South Africa, Australia and Brazil: Importance of early detection and lifestyle advice. Atherosclerosis. $2018 \quad$ Oct;277:470-476. doi: 10.1016/j.atherosclerosis.2018.06.822.

5. Nasseryan J, Hajizadeh E, Rasekhi A, Ahangar $\mathrm{H}$. Investigation factors affecting the first recurrence of coronary artery disease in patients undergone angioplasty using cox survival model. Med J Islam Repub Iran. 2016 Nov 8;30:441.
6. Ribeiro AL, Duncan BB, Brant LC, Lotufo PA, Mill JG, Barreto SM. Cardiovascular Health in Brazil: Trends and Perspectives. Circulation. 2016;133(4):422-433.

7. Roffi M., Patrono C, Collet JP, Mueller C, Valgimigli M, Andreotti F, et al. 2015 ESC Guidelines for the management of acute coronary syndromes in patients presenting without persistent ST-segment elevation: Task Force for the Management of Acute Coronary Syndromes in Patients Presenting without Persistent ST-Segment Elevation of the European Society of Cardiology (ESC). European Heart Journal. 2016:37(3):267-315.

8. Mehta SR, Cannon CP, Fox KA, Wallentin R, Boden WE, Spacek R, et al. Routine vs selective invasive strategies in patients with acute coronary syndromes: a collaborative meta-analysis of randomized trials. JAMA 2005;293(23):2908-2917.

9. Denktas AE, Anderson HV, McCarthy J, Smalling RW. Total ischemic time: the correct focus of attention for optimal ST-segment elevation myocardial infarction care. JACC Cardiovasc Interv. 2011;4(6):599-604.

10. Roffi M, Patrono C, Collet JP, Mueller C, Valgimigli M, Andreotti F, et al. 2015 ESC Guidelines for the management of acute coronary syndromes in patients presenting without persistent ST-segment elevation: Task Force for the Management of Acute Coronary Syndromes in Patients Presenting without Persistent ST-Segment Elevation of the European Society of Cardiology (ESC). Eur Heart J. 2016;37(3):267-315.

11. Palmiero P, Zito A, Maiello M, Cecere A, Mattioli AV, Pedrinelli R, Scicchitano P, CicconeMM.PrimaryPrevention Of Cardiovascular Risk In Octogenarians By Risk Factors Control. Curr Hypertens Rev. $2019 \quad$ Feb $11 \quad 11$ doi: 10.2174/1573402115666190211160811].

12. Ghasemi M, Mehrpooya M, Ghasemi F, Shahbazi F. OneStage Angioplasty and Stenting of Ostium of Left Common Carotid Artery and Stenting of Left Internal Carotid Artery. Acta Med Iran. 2017 Jan;55(1):79-81.

13. Colombo A, Azzalini L. 40 Years of coronary angioplasty: success comes from skills and determination!. G Ital Cardiol (Rome). 2017 Sep;18(9):623-624. doi: 10.1714/2741.27944.

14. Meier B. His master's art, Andreas Grüntzig's approach to performing and teaching coronary angioplasty. EuroIntervention. 2017 May 15;13(1):15-27. doi: 10.4244/EIJV13I1A2.

15. Funayama N, Muratsubaki S, Kawahatsu K, Miyata M, Katou Y, Oikawa T. Clinical outcomes of SeQuent Please paclitaxel-coated balloons for de novo small coronary artery lesion in a Japanese multicenter post-approval registry. Coron Artery Dis. 2019 Sep 11. doi: 10.1097/MCA.0000000000000782.

16. Ahmad T, Chithiraichelvan S, Patil TA, Jawali V. Surgical retrieval of entrapped coronary angioplasty guidewire from the aorta. Asian Cardiovasc Thorac Ann. 2016 Jan;24(1):81-84. doi: 10.1177/0218492314546496. Epub 2014 Jul 27.

17. Guimarães Neto WP, De França JCQ, De Godoy MF, Dos Santos MA, Pivatelli FC, et al. (2019) Impact of the Angioplasty Procedure in Cohort of the

18. Patients Older than 80 Years with Anemia: An Observational Study. J Cardiovasc Dis Diagn 7: 361. doi: 10.4172/2329-9517.1000361 
19. Junior JB, Buchalla M, Valeriano RC, Novelli D, Fernandes HT, et al. (2018) Statistical Approach to Longitudinal Retrospective Study with Over 1,000 Participants Shows Main Predictors of Cardiovascular Disease for Angioplasty. J Cardiol Curr Res 11(1): 00368. DOI: $10.15406 /$ jccr.2018.11.00368.
20. Novelli D, Buchalla M, Cury MBB, Negrão RR, Junior JB (2018) Longitudinal Retrospective Study with over 500 Participants Shows Main Continuous Predictors for Angioplasty: Clinical Trial. Int J Cardiovasc Res 7:3. doi: 10.4172/2324-8602.1000351.
This work is licensed under Creative Commons Attribution 4.0 License

To Submit Your Article Click Here: Submit Article
Ready to submit your research? Choose Auctores and benefit from:

* fast, convenient online submission

* rigorous peer review by experienced research in your field

* rapid publication on acceptance

* authors retain copyrights

* unique DOI for all articles

* immediate, unrestricted online access

At Auctores, research is always in progress.

Learn more www.auctoresonline.org/journals/clinical-cardiology-andcardiovascular-interventions 